\title{
Bringing about Sustainable Change in Product Development: Theory versus Practice
}

\author{
Elli Verhulst ${ }^{1,2}$ and Casper Boks ${ }^{2}$ \\ ${ }^{1}$ Department of Design Sciences, Artesis University College Antwerp, \\ Ambtmanstraat 1, 2000 Antwerp, Belgium \\ elli.verhulstaartesis.be \\ ${ }^{2}$ Department of Product Design, Faculty of Engineering Science and Technology, \\ Norwegian University of Science and Technology, \\ Kolbjørn Hejes Vei 2B, 7491 Trondheim, Norway
}

\begin{abstract}
Using a change management perspective, this paper studies the implementation process of life cycle thinking and sustainable design in practice, based on empirical data from eight firms involved in product development. The data indicate that different firms take different trajectories and approaches towards implementation, which in turn depends on a number of human factors, including participation of employees, training, resistance to change etc. As a result of this study, a model for the implementation of sustainable design is presented. Firms can use the model and the insights for the improvement and adaptation of existing methodologies and for choosing a fitting approach for integrating life cycle thinking.
\end{abstract}

Keywords: sustainable design, life cycle thinking, implementation process, implementation approach, case study.

\section{Introduction}

The translation and implementation of academic theories, concepts and innovations into successful business applications is a well-known challenge. In the field of sustainable design such challenges exist as well [1]. This field has, since the early nineties, passed through a series of transitions, making this implementation process gradually more complex, as these transitions have for example demanded a shift from a product to a systems perspective, from an environmental to a sustainability context, and from concept development to technology transfer and commercialization [2]. Academic improvements in addressing sustainability criteria in product development have been proposed by many scholars, often in the form of methods and tools [3]. Other scholars propose methodologies for sustainable product development -also referred to as life cycle thinking- that suggest when and how sustainability criteria should be taken account of and which tools may (or even should) be used [4]. Most of these tools focus merely on methodological aspects. Moreover, many of these existing roadmaps offer support for pilot initiatives only, and/or are based on pilot studies only, whilst the main challenge lies with moving from successful pilot initiatives to recurring initiatives that lead to long-term 
sustainability [5]. Literature on sustainability in business offers some approaches that cover a long-term implementation process on a general level within the firm [6]. However in the field of sustainable design, such a holistic view on the complete implementation process is lacking, both from a theoretical and from an empirical perspective.

The field of change management profoundly studies change processes with the aim to support and streamline this complex and lengthy process. A holistic view is thereby taken, whereby methodologies, as well as different approaches and variable influencing factors consider the aim to successfully reach the change. Lewin for example proposed that a process of change can be divided into three stages: unfreezing, changing and refreezing [7]. There is considerable consensus on this three stages model of organisational change [8]. Literature on change management also indicates different approaches that can guide an organisation through these subsequent stages of a change process [9], [10]. These approaches emphasize e.g. a directive, educative or participative approach of the process to reach the goals of the change. Factors that influence a change process can be related to practical and organisational issues, which in turn may have a substantial relationship to personal or emotional factors. This latter group of factors, the human dimension of the implementation process, is so far insufficiently studied in sustainable design research [1,11-13]. This human dimension forms the subject of a broader study that focuses on human factors and how they influence the implementation process of sustainability criteria in product development [14], [15]. This paper forms a part of that study, but limits its focus to the implementation approach that is followed and the process steps that are taken during this specific implementation process.

The aim of this paper is to provide insights - based on an empirical study - on the overall implementation process of integrating life cycle thinking in product development and on approaches that can be taken to reach the sustainability targets. Knowledge on change management is thereby used to broaden insights on the followed trajectories in business. Two research questions are formulated:

I. Which steps are taken in the implementation process of sustainability criteria in product development that support the transformation of academic knowledge into practical applications?

II. Which approaches are used for the implementation process of sustainability criteria in product development?

\section{Research Approach}

A qualitative case study research approach is used to provide answers to the two research questions and to offer insights on similarities and distinctions between different firms on the implementation process. The empirical data are also used to shed light on the specificity of sustainability as the subject of the incorporation process. Apart from a geographical location in the Benelux for practical reasons, two criteria have been used to select eight case study firms, making it possible to obtain a good understanding of the phenomenon under study [16]: firms were selected that incorporate an own product development department, and have taken at least the first steps towards the integration of sustainability criteria in the firm and in product 
development. Interviews with company representatives related to both product development and the process of implementing sustainability criteria in product development or in the firm are the main source of data, which is supplemented by archive data, company documentation and observations [17]. The analysis of the empirical data has been done in two main stages, of which the first has a descriptive nature, whereas the latter is explanatory. In a first step, different topics that have been touched upon in the data set were coded and subsequently clustered. A second part of this step contained the description of the phenomenon under study, i.e. the implementation process of sustainability in product development, subsequently followed with an analysis of each case. This step provides insights in the approach, activities a firm has gone through in the implementation of sustainability criteria in the firm. In a last step, a cross-case analysis between the different cases was made, subsequently followed by the development of a model for the sustainable design implementation process.

\section{$3 \quad$ Study Findings}

The empirical data for this study is based on almost 20 hours of interview data from eight different medium and large sized Belgian and Dutch firms, from various sectors (including the furniture, electronics, chemical and construction industry). These interview data have been supplemented with observations during meetings with the informants, and several documents such as year reports, sustainability reports and folders, and internal documents. From the respondents that cooperated, eight had clearly defined responsibility in implementing sustainability within the firm and the product development process. The functions of these people vary within the different firms: as a coordinator of CSR, coordinator of quality, health and environment, communication manager, or R\&D manager.

\subsection{Process Steps}

The first research question addressed in this paper concerns the process steps of the implementation process that firms pass in practice. A first stage is indicated in literature to unfreeze or prepare for the change, which in this case is the implementation of sustainable design. Table 1 gives an overview of the activities that the case firms dealt with in this preparatory stage in the eight cases. The table indicates that in only one of the cases, all aspects of the preparatory stage are fulfilled. Knowledge on change management was indicated as a basis for any change to occur in this firm. In the other firms however, one or more aspects of this preparatory stage are not prepared or carried out. In three of the cases, less than two elements have been achieved. The empirical data however indicate that independent initiatives are performed to initiate the integration of sustainability criteria, without the preparatory stage being (fully) achieved. The development of a vision, mission, strategy and planning were thereby indicated in several cases to take place after the completion of these independent initiatives. This indicates that the succession of activities during the first stages of the implementation process differs from the activities of this preparatory stage suggested by literature as conditions for success. 
Table 1. Overview of activities in preparatory stage

\begin{tabular}{|lccccccc|}
\hline Case & $\begin{array}{c}\text { Establish need for } \\
\text { sustainability }\end{array}$ & $\begin{array}{c}\text { Build change Vision and } \\
\text { team }\end{array}$ & $\begin{array}{c}\text { Strategy } \\
\text { mission }\end{array}$ & $\begin{array}{c}\text { Strategy for product } \\
\text { geveral level }\end{array}$ & $\begin{array}{c}\text { Planning } \\
\text { Case 1 }\end{array}$ \\
Case 2 & $\mathrm{x}$ & $\mathrm{x}$ & $\mathrm{x}$ & $\mathrm{x}$ & $\mathrm{x}$ & - \\
\hline Case 3 & $\mathrm{x}$ & $\mathrm{x}$ & - & $\mathrm{x}$ & $\mathrm{x}$ & $\mathrm{x}$ \\
\hline Case 4 & - & - & - & - & - & $\mathrm{x}$ \\
\hline Case 5 & $\mathrm{x}$ & $\mathrm{x}$ & $\mathrm{x}$ & $\mathrm{x}$ & $\mathrm{x}$ & - \\
\hline Case 6 & $\mathrm{x}$ & - & $\mathrm{x}$ & $\mathrm{x}$ & $\mathrm{x}$ & $\mathrm{x}$ \\
\hline Case 7 & - & - & - & - & $\mathrm{x}$ & $\mathrm{x}$ \\
\hline Case 8 & - & - & - & - & $\mathrm{x}$ & $\mathrm{x}$ \\
\hline
\end{tabular}

The data thus demonstrates that the development of a vision, mission and general strategy are not necessarily needed as a first step, and more importantly, this implies that a product development department can take the role of initiating the integration of sustainability criteria in product development. However, in order to bring the incorporation of sustainability to a higher, broader and permanent level within the firm, the different elements of the preparatory stage need to be further developed and supported by the management, as illustrated by the following quote:

'We first did some independent, smaller projects with external partners, more because we didn't really know what we wanted to do, so more isolated initiatives. But now there has been decided to take a look at sustainability more profoundly, especially towards the end of the lifecycle of our products. This direction comes from the top management, but the projects are proposed by the $R \& D$ managers.' (product developer of case 7)

A second stage in a change process -described as the change stage in literature on change management- includes several interventions. In all cases, different activities, projects and actions that are considered to support changes towards sustainability in the firms, were found to take place in the eight case firms. Different interventions were indicated to take place simultaneously as well as consecutively. This suggests that completing a pilot project functions rather as a startup of the implementation of sustainability criteria in product development, but also that multiple product development processes need to be performed before full integration of sustainability criteria in design can be reached. Five types of interventions are identified to occur in practice: product development projects with specific sustainability goals (in cases 1, 2 and 7) are projects that focus specifically on certain aspects of sustainability, e.g. on the recyclability of the product's materials. Such projects are considered to run parallel with other, generic product development projects within the firm. Product development projects with sustainability criteria incorporated in the firm's product development process. In four of the cases, an adapted methodology was developed and spread throughout the employees within or connected with the product development 
department. In case 3 for example, sustainability criteria that fit the priorities of the firm, i.e. recyclability of materials, have been included in the different product development process steps starting from the product specifications. In this firm, small but continuous improvements lead to further integration of sustainability criteria in the product development process. In several of the cases, specific sustainability projects occur on a general level within the firm. This type of project is directed to raise awareness with the employees on sustainability issues, e.g. a yearly social day (case 7), to improve the overall sustainable profile of the firm, such as efforts on energyefficiency (case 7), or to improve the overall sustainable image of the firm, such as brochures on sustainability in the firm (cases 3 and 5) or a (renewed) website with sustainability information (case 3). Research projects on the subject of sustainability occurred in all cases. In cases 2 and 7, this occurs in the own research department of the firm, as well as in cooperation with external experts and partners. All firms indicated to cooperate with research institutes and universities, either by collaborating in research projects or by outsourcing research to those institutes that are aimed at improving sustainability efforts in the firm. This sort of intervention broadens the knowledge on certain sustainability aspects and strengthens the external network. Interventions that aim at supporting the overall implementation process of sustainability criteria in product development are interventions that are not necessarily related to product development projects or to the subject of sustainability, but that are considered to support the implementation process. Training and communication are two examples of such interventions (cases 1, 2, 3 and 5).

\subsection{Implementation Approach}

The second research question in this paper concerns the implementation approach that is applied in practice for incorporating sustainability criteria in product development. Table 2 offers an overview of the implementation approaches used in the eight cases in this study.

Table 2. Implementation approach used in eight cases, criteria based on [9]

\begin{tabular}{|c|c|}
\hline Cases & Implementation approach \\
\hline Case 1 & $\begin{array}{l}\text { People are central } \\
\text { Change is seen as change in human behaviour } \\
\text { Return is respect and appreciation } \\
\text { Empowerment of people is important } \\
\text { Involvement of all employees is the goal }\end{array}$ \\
\hline Case 2 & $\begin{array}{l}\text { Changing is learning: change people with own motivation and learning capacity } \\
\text { Only people that come in contact with product development (PD) and } \\
\text { sustainability issues are involved and trained } \\
\text { Many procedures are used and followed } \\
\text { 'Learning from mistakes' }\end{array}$ \\
\hline Case 3 & $\begin{array}{l}\text { People are central } \\
\text { Change is seen as change in human behaviour } \\
\text { Return is respect and appreciation } \\
\text { Empowerment of product development department is high } \\
\text { Product development and sales are strongly involved, production less }\end{array}$ \\
\hline
\end{tabular}


Table 2. (continued)

\begin{tabular}{|ll|}
\hline Case 4 & $\begin{array}{l}\text { Opportunities lead towards sustainability } \\
\text { Opportunities are facilitated and supported } \\
\text { Implementation is not clearly planned } \\
\text { Only employees involved in the PD process are involved in sustainability issues }\end{array}$ \\
\hline Case 5 & $\begin{array}{l}\text { Change is very well prepared - rational process } \\
\text { Goals, measures and results are important } \\
\text { Many procedures are used and followed } \\
\text { Results are used as examples of best practices } \\
\text { Involvement of all employees is the goal }\end{array}$ \\
\hline Case 6 & $\begin{array}{l}\text { Strong focus on combined advantages of sustainability perspective } \\
\text { Opportunities are facilitated and supported } \\
\text { Change people with own motivation and learning capacity } \\
\\
\text { Procedures are developed and applied in practice } \\
\text { Goals and measures are important } \\
\text { From voluntary towards obligatory implementation in the PD process }\end{array}$ \\
\hline Case 7 & $\begin{array}{l}\text { Change people with own motivation and learning capacity } \\
\text { Project-based } \\
\text { Involvement of all employees is the goal, apart from production }\end{array}$ \\
\hline Case 8 & $\begin{array}{l}\text { Methods and tools are developed to support the design process } \\
\text { Change people with own motivation and learning capacity } \\
\text { Voluntary basis of implementation in the product development process } \\
\text { Project-based } \\
\text { Involvement of all employees is the goal }\end{array}$ \\
\hline
\end{tabular}

The empirical data indicate that few of the firms use a generic approach for incorporating sustainability criteria as 'a change as many others', whereby an approach is consciously used that supports all changes that occur within that specific firm (cases 2 and 5):

'We identify the issue -like the green stuff- we find an approach, we run a pilot, we map it on the process, we update procedures and then we identify the training needs. That is done for all changes here. We always go through that same cycle.' (case 2)

All firms however adapted the implementation approach to the firm's culture. An adaptation to the firm's culture is mentioned in literature as an important point of attention to raise the chance of successful implementation [10]. In practice, this adaptation seems to occur naturally, but not always consciously. The data indicate that this leads to interesting differences in approaches that emphasize other elements of the implementation process. In case 4 , the creation of new challenges formed the main element of sustainable innovations. In some cases, control, structure and organization form the dominant characteristic in the applied approach (cases 2 and 5), whilst in other cases, the employees are considered as a central element in the process, whereby change is seen as a shift in human behaviour (cases 1 and 3). In half of the cases, change is 
considered mostly as a learning process, whereby the motivation and learning capacity of the employees is seen as an important element that can provide the changes needed (cases 2, 6,7 and 8). The empirical data thus indicate that different approaches can lead towards sustainability in product development, depending on the culture of a firm. On the other hand, the subject of change - sustainability criteria in product development - also implies specific points of interest that need attention during the implementation process, such as the complexity of the subject, a lack of clarity on the concept of sustainability and a lack of clear and uniform measurement systems. This adaptation to the subject of sustainability seems to occur less in the firms studied.

\section{Discussion}

The empirical data in this study indicate a different order of activities during the implementation process of life cycle thinking in design in practice, than the order of activities as suggested in literature, especially in the unfreeze stage. In practice, this stage consists of independent projects that include sustainability aspects, whereas in literature, this unfreeze stage entails the development of a vision, mission, strategy, etc. These activities are indicated to take place in the cases, but often after completion of several of the individual projects. Several interventions are mentioned in the data set to take place both in the unfreezing as in the change stage, whereby different types of projects occur that support the translation of academic knowledge into practical applications. Some of these projects aim at passing theory and knowledge on sustainable design towards employees and partners, whilst other projects aim at supporting the implementation process and its approach. In all cases, external partnerships, amongst others with universities, are created to strengthen the link between theory on sustainable design and its application in the firm. This type of projects is thus recognized in all cases, but might need further exploration to support the implementation process more profoundly.

The insights on the implementation process steps and approaches, together with the results of a broader study on the implementation of sustainable design, have been used as input for the development of a descriptive model. This model shows the main process stages of the implementation sustainable design, as well as it includes human factors that came forward in the broader study. The model combines theoretical insights that have been gathered in a review of sustainable design and change management literature- with the understandings that were gained in practice. This combination of theoretical and empirical insights offers valuable indications on the process steps and human factors for scholars and practitioners to raise their understanding on the implementation process of sustainable design and the human factors within (Fig. 1). 


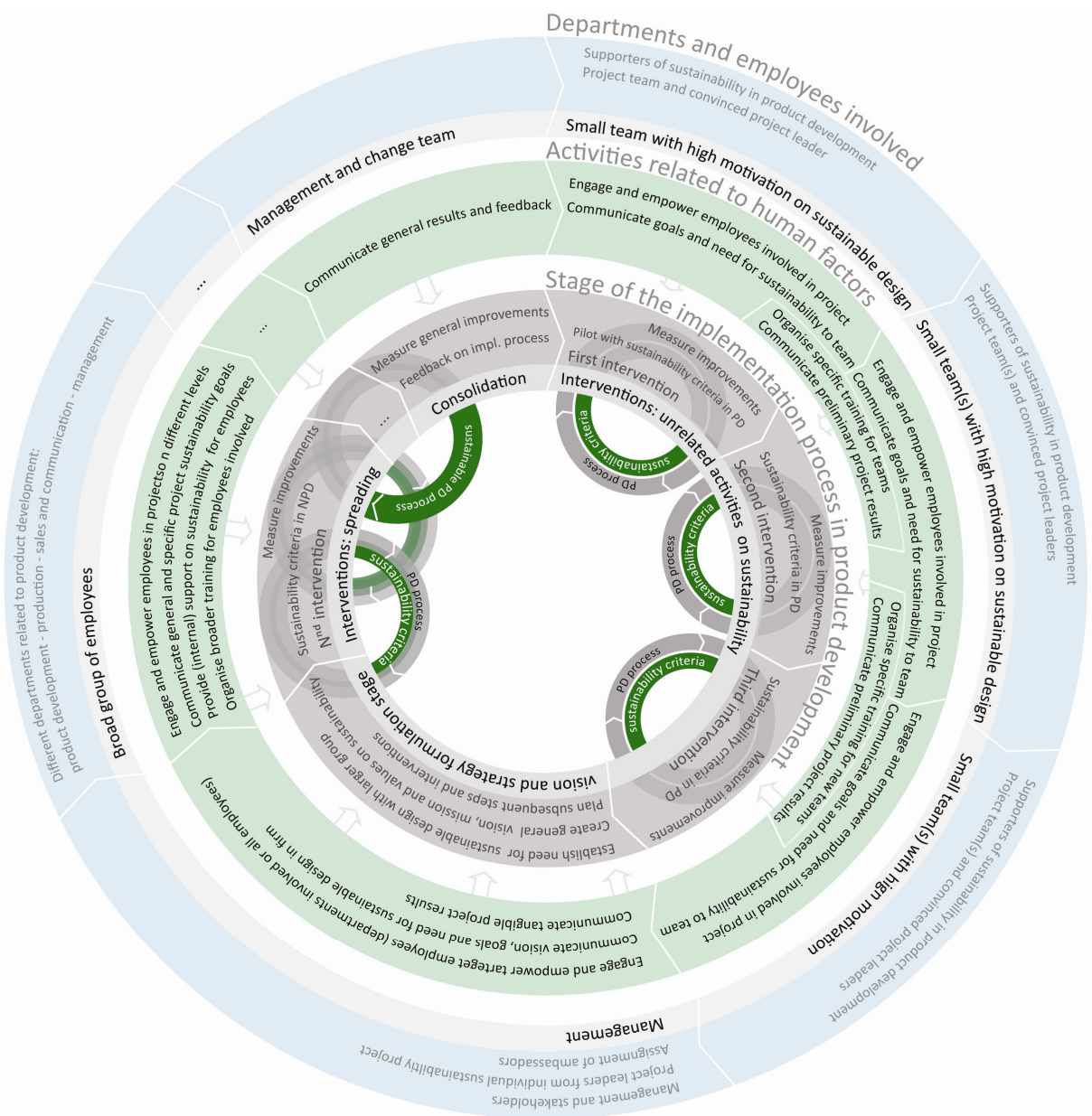

Fig. 1. Model on sustainable design implementation

The model consists of three circles that represent I) the implementation process steps in the inner circle, II) human factors that have been indicated as significant to take account of in each process step, represented in the middle circle, and III) employees or departments that come forward in the study to be involved in the corresponding step of the implementation process, represented in the outer circle. The inner circle offers an overview of the implementation process on a long term. It indicates how firms evolve from one or more pilot projects on sustainable design towards an integrated sustainable design process. The model thereby places the product development process in the broader perspective of the implementation process.

Apart from the process stages in the inner circle, the model presents which human factors are indicated in the study as significant to be incorporated or taken account of in the different implementation stages, such as engaging employees. Several of these 
human factors appeared to be recurrent in the different stages, e.g. in the subsequent interventions, but directed to another -and growing- group of employees. This expansion of the group of employees involved explains the importance of the third circle in the model, which shows the (new) employees or departments on which the human factors are indicated to apply to, as for those people, that moment forms the start of the implementation of sustainable design. The outer circle also indicates a small number of employees that is indicated to be involved in the beginning of the implementation process. This group of employees is found to grow slowly at first, but suddenly this growth was indicated to be much faster after the development of a general vision and strategy on sustainability in product development and in the firm.

Further research could focus on a validation of the descriptive model by applying it in practice from the start of the implementation process of sustainable design and measuring the success of the process. Another direction for future research is suggested to focus on the implementation process of sustainable design in firms that are active in the same sector and that have a similar organisational culture, with a focus on the choice and application of a specific implementation approach in comparable situations.

\section{Conclusion}

This paper studies the implementation process of life cycle thinking in practice, starting from empirical data. Knowledge on change management is thereby used to shed light on the processes that occur and the approaches that are taken by the participating firms. The knowledge from change management and the empirical data together provide a holistic view on the complete implementation process in practice, which is currently lacking in the field of sustainable design, both from a theoretical point of view as from an empirical perspective. This study indicates that different trajectories are followed that depend on the context of the firm. Moreover, variable approaches are indicated to occur in practice in which differences in emphasis are put on methodology, participation of employees, training, etc. A descriptive model is presented in the paper that shows the relationships between three levels in the implementation process of sustainable design: process, human factors and employees and departments involved. It offers a visual overview on how the process can be approached on these three levels. To both firms and scholars, this model and the insights from this study for the improvement and adaptation of existing methodologies may be useful for both scholars and firms, and guide them in choosing a fitting approach for integrating life cycle thinking in product development.

\section{References}

1. Baumann, H., Boons, F., Bragd, A.: Mapping the green product development field: engineering, policy and business perspectives. Journal of Cleaner Production 10, 409-425 (2002)

2. Boks, C., McAloone, T.: Transitions in Sustainable Product Design Research. International Journal of Product Development 9(4), 429-449 (2009) 
3. O'Hare, J.A.: Eco-innovation tools for the early stages: an industry-based investigation of tool customization and introduction. PhD thesis at University of Bath, Department of Mechanical Engineering, UK (2010)

4. Brezet, Van Hemel: Ecodesign: a promising approach to sustainable production and consumption. Rathenau Institute. TU Delft and UNEP, Paris (1997)

5. Wilson, E., MacGregor, G., MacQueen, D., Vermeulen, S., Vorley, B., Zarsky, L.: Innovating for environment and society: an overview. IIED Briefing Business models for sustainable development (2009)

6. Dunphy, D., Griffiths, A., Benn, S.: Organizational change for corporate sustainability, 2nd edn. A guide for leaders and change agents of the future. Routledge, New York (2007)

7. Lewin, K.: Field Theory in social science. Greenwood, NY (1951)

8. Kanter, et al.: Managing change in organisations. Simon and Schuster, NY (1992)

9. de Caluwé, L., Vermaak, H.: Leren veranderen. Een handboek voor de veranderkundige. Kluwer, Deventer (2006)

10. Kotter, J.P., Schlesinger, L.A.: Choosing strategies for change. Harvard Business Review, 130-139 (July-August 2008) (reprint of original article from 1973)

11. Verhulst, E., Boks, C., Stranger, M., Masson, H.: The human side of Ecodesign from the Perspective of Change Management. In: Advances in Life Cycle Engineering for Sustainable Manufacturing Businesses - Proceedings of the 14th CIRP Conference on Life Cycle Engineering, pp. 107-112 (2007)

12. Boks, C.: New academic research topics to further ecodesign implementation: an overview. International Journal of Product Development 6(3/4) (2008)

13. Boks, C.: The Soft Side of Ecodesign. Journal of Cleaner Production 14(15-16), 1346-1356 (2006)

14. Verhulst, E., Boks, C., Masson, H.: Colour-print thinking to measure and support human factors in the implementation process of sustainability criteria in design. In: Proceedings of EcoDesign 2009, Sixth International Symposium on Environmentally Conscious Design and Inverse Manufacturing, Sapporo, Japan, December 7-9 (2009)

15. Verhulst, E., Boks, C.: The role of human aspects in design for sustainability strategies and approaches. In: Electronic Pre-Proceedings of APMS 2010 International Conference, Cernobbio, Italy, October 11-13 (2010)

16. Patton, M.Q.: Qualitative Evaluation and Research Methods. Sage, US (1990)

17. Yin, R.K.: Case Study Research, 3rd edn. Applied Social Research Methods Series, vol. 5. Sage Publications, USA (2003) 